\title{
Para Avaliar Propostas de Avaliação do Ensino Superior
}

\section{Valdemar Sguissardi}

Universidade Metodista de Piracicaba (Unimep)

No âmbito do processo de modernização neoliberal que afeta todas as instâncias do Estado e da sociedade brasileira hoje, destaca-se o movimento de avaliação do ensino superior. Este artigo objetiva, por um lado, recuperar as origens, as motivações e a identidade desse movimento e, por outro, estabelecer alguns parâmetros para o exame crítico das diferentes propostas de avaliação desse nível de ensino, encaminhadas por instituições públicas e privadas e outras entidades ou organizações sociais. Concluindo, o autor propõe aos pesquisadores da área (ensino superior) uma pauta de pontos da temática da avaliação do ensino superior que, problematizados, poderiam tornar-se objetos de futuros estudos e pesquisas.

\section{Introdução}

Na universidade, como na vida em geral, é necessário questionar a ordem estabelecida e resistir a modismos de todo o gênero. Parece contraditório aceitar a ordem e deixar-se embalar pela última moda. Mais importante que explicar essa aparente contradição é perguntar sobre o significado de certos modismos que tomam conta de nações, governos, instituições, grupos e indivíduos singulares com a feição de irrecusáveis dogmas, merecedores de cruzadas heróicas. O dogma impõe a fé e a obediência cegas e condena como heréticos ou mal-intencionados os que se recusam à prática dos atos assim idealizados. 
- Conclamamos os Cidadãos Bem-intencionados Deste País Para Que se Juntem a Nós Pelo Resgate da Qualidade da Educação no Brasil! ${ }^{1}$

- A Qualidade total revolucionando o ensino superior. ${ }^{2}$

- Qualidade: Sobrevivência ${ }^{3}$

- A Qualidade e a Sobrevivência das Universidades ${ }^{4}$

- Avaliação Universitária Global: Um Novo Caminho em Busca da Excelência ${ }^{5}$

Com a mesma força de avalanche irresistível com que se estendeu sobre o universo empresarial brasileiro, depois de ter germinado no terreno fértil do milagre japonês, do neoliberalismo thatcheriano, do fim da Guerra Fria etc, a Filosofia da Qualidade Total ${ }^{6}$ invade também o imunodeficiente sistema educacional brasileiro. Rapidamente, é saudada por muitos, "sérios e responsáveis", como panacéia para os imensos males históricos desse sistema. O ensino superior-público e privado (confessional ou mercantil) - constitui-se em alvo privilegiado dessa nova guerra santa.

O modismo da Filosofia da Qualidade Total, que arrisca metamorfosear-se em dogma eclesiástico-científico de longa duração, no caso do ensino superior está servindo-se, para sua empreitada, dentre outras armas, do mecanismo da Avaliação Universitária Global ou da Avaliação, simplesmente.

\footnotetext{
' Fecho do documento "Pacto da Qualidade pela Educação - Moção dos Cidadãos Brasileiros". Instituto Euvaldo Lodi (IEL). Construindo a Pedagogia da Qualidade. Encontro Nacional Indústria-Universidade sobre Pedagogia da Qualidade. Anais... (apud Assmann, 1993',p.62-64).

${ }^{2}$ Item do Temário Preliminar do II Congresso Brasileiro da Qualidade no Ensino Superior. São Paulo, 12-14 ago. 1994.0 termo "qualidade" e a expressão "qualidade total" aparecem 18 vezes nesse documento

' Item da ementa do curso "Os Fundamentos da Qualidade Total nas Instituições de Ensino Superior", que precede e integra a programação do congresso referido na Nota 2.

${ }^{4}$ Item do Temário Preliminar do II Congresso Brasileiro da Qualidade no Ensino Superior. São Paulo. 12-14 ago. 1994.

${ }^{5}$ Id.Ibid.

${ }^{6}$ Sobre o conceito e discussão do significado da "onda" filosofia da qualidade total e qualidade, entendida nesta perspectiva, cf. Assmann (1993b e 1994) e Silva (1994).
} 
Valha para ilustrá-lo a realização simultânea, nada casual, em 12,13 e 14 de agosto de 1994, no Centro de Convenções Rebouças, em São. PauloSP, do II Congresso Brasileiro da Qualidade no Ensino Superior, do I Congresso Brasileiro de Gestão Universitária e do I Congresso Brasileiro de Avaliação Universitária, além de dois Cursos Pré-Congressos denominados "Os Fundamentos da Qualidade Total nas Instituições de Ensino Superior" e "A Qualidade Total Universitária: Metodologia de Implantação", no mesmo local, no dia 11 de agosto de 1994. A promoção foi do Instituto Brasileiro da Qualidade em Serviços (Ibraqs), com o apoio científico-cultural de um conjunto de entidades ligadas ao ensino superior privado (Sindicato das Entidades Mantenedoras de Estabelecimentos de Ensino Superior no Estado de São Paulo - Semesp e Associação Brasileira de Mantenedores do Ensino Superior - ABM, entre outras) e tendo como presidente de honra a Prof. ${ }^{a}$ Dr. Jeanete L. M. de Sá, delegada do MEC em São Paulo.

As numerosas (mais de uma centena) experiências de avaliação realizadas no ensino superior, nos últimos dez a quinze anos, ${ }^{7}$ talvez tenham estado em sua maioria imunes às motivações que mobilizam os atuais defensores da Filosofia da Qualidade. Entretanto, uma melhor análise das origens dessa filosofia e da gênese das preocupações, especialmente oficiais e de organismos empresariais privados, no Brasil, assim como em outros países - Portugal, Inglaterra, França, Dinamarca etc. —, mostraria como as raízes motivacionais dessas duas frentes, aparentemente isoladas, enraízam-se num mesmo solo: o imperativo da modernização (cf. Lima, Afonso, 1993, p.33-49), a globalização da economia; a ciência, a tecnologia e a informação transformadas em forças produtivas; o fim do fordismo (como organização industrial e modelo de desenvolvimento); o advento do neotaylorismo; e a reestruturação do Estado nos moldes da cartilha neoliberal (cf. Sguissardi, Silva Jr, 1994, p.4-5).

\footnotetext{
${ }^{7}$ Cf. Paul, Ribeiro, Pilatti (1992. p.141-167). Esses autores apresentam uma relação de meia centena de experiências de avaliação no ensino superior (163-165), classificados em dois tipos básicos - "diagnóstico'/conhecimento e "acompanhamento" - e realizadas em três dimensões: da instituição, do ensino de graduação e do curso.
} 
Multiplicam-se as propostas e experiências de avaliação fundadas nas rnais diferentes filosofias e concepções de sociedade, de desenvolvimento social, de universidade e do próprio mecanismo da avaliação. Implantam-se propostas e experiências extremamente diversificadas quanto à sua abrangência (instituições, níveis de ensino, cursos, atividades-fim, atividades-meio), à sua concepção e à forma de sua implantação. Ao observador ingênuo, que acredita na neutralidade político-científica da instituição universitária e na avaliação como um bem universal, ocorreria pensar que isto é oportuno e positivo para instituições que contrairiam, todo o dia, imensa dívida social, por serem públicas ("sustentadas pelas verbas da arrecadação fiscal") ou por serem privadas ("sustentadas pela retribuição do trabalho alienado de seus alunos").

Distinguir as propostas e práticas de avaliação conducentes a uma universidade produtora de saber e crítica daquelas propostas e práticas tendentes a "ampliar e tornar rnais eficaz o funcionamento do sistema escolar [universitário] dirigido para a reprodução da ordem estabelecida e da ótica do capital"8 - hoje em grande medida inspiradas nos princípios traduzidos pela Filosofia da Qualidade Total — é uma tarefa urgente que se impõe aos que pretendem contribuir para a melhoria e a democratização da universidade. Assumir essa tarefa significa enfrentar um dos grandes desafios postos pela crise em que está mergulhado o sistema universitário brasileiro e, por que não dizê-lo, universal. Em outros termos, a questão fundamental é como avaliar as propostas (e as práticas) de avaliação para o ensino superior e para a universidade, sejam elas originárias do poder público, das próprias instituições universitárias públicas ou privadas, de entidades sindicais universitárias, de grupos de intelectuais orgânicos ou não.

A crítica necessária a diferentes propostas de avaliação de qualquer origem e significado, entretanto, não exime ninguém da exigência ético-profissional e ético-social de questionar a ausência de efetivos pro-

* Sobre esses dois modelos de avaliação institucional, cf. M. L. Cardoso (1991. p. 18s). 
jetos de universidade (e de políticas acadêmico-científicas), os vícios administrativos, a malversação dos meios e recursos financeiros e científicopedagógicos, bem como, no dizer de M. L. Cardoso, de questionar

...o despreparo profissional e o pouco empenho no trabalho que encontramos hoje na Universidade brasileira por parte de alguns docentes, mesmo quando as condições de trabalho oferecidas, ainda que precárias, permitem e até facilitam a realização de estudos pós-graduados, bem como a preparação de cursos de qualidade e a realização de pesquisa.

Avaliar o ensino superior e a universidade é preciso e urgente, mas é necessário saber, antes, de que avaliação se está falando. Para tanto, impõe-se de antemão o exercício da crítica às diferentes propostas de avaliação, nesta época de tantos apelos e urgências fundadas em princípios e conceitos tidos como de validade universal. Buscar estabelecer alguns parâmetros para tal exercício é o principal objetivo desta reflexão e do presente texto. Secundariamente, pretende-se levantar uma pauta de pontos da temática da avaliação que, problematizados, deveriam ser objeto de aprofundamento teórico/crítico dos pesquisadores do ensino superior em futuros estudos e pesquisas.

Esses objetivos deverão ser alcançados interrogando-se e examinando-se as reflexões (e experiências) de diversos autores e entidades que têm discutido a universidade e/ou a avaliação ${ }^{5}$ no ensino superior nos anos recentes. ${ }^{9}$

A única originalidade ou relevância aqui pretendida é a de recuperar importantes contribuições desses autores ou dessas experiências e de produzir um instrumento de análise com razoável consistência teórica e utilidade prática, no esforço necessário para fazer da avaliação e especialmente da avaliação institucional um instrumento eficaz de democratização da universidade brasileira.

\footnotetext{
${ }^{9}$ Todos os que se encontram indicados nas referências bibliográficas, no final deste trabalho, especialmente M. L. Cardoso
} 


\section{Origens do atual processo de avaliação do ensino superior e razões para sua implementação}

É no final dos anos 50 e nos anos 60, culminando com a Reforma Universitária $^{10}$, que se pode localizar as origens do atual processo da avaliação no ensino superior, ainda que ele tenha sofrido significativas transformações em razão das mudanças nos principais fatores estruturais e conjunturais que o condicionam.

No período nacional-desenvolvimentista, que antecedeu o golpe militar de 64, as características democrático-populistas do regime vigente e a intensa mobilização da sociedade civil (especialmente do setor estudantil) possibilitaram um profundo questionamento do modelo universitário brasileiro, incapaz de responder às exigências de seu tempo. Assim como em toda a história da universidade e das instituições, os momentos cruciais de suas reformas, frustrados ou não, vêm precedidos de processos de avaliação. Isto permite a Kipnis (1991, p.3) afirmar que, naquela ocasião,

...a proposta de uma revisão do projeto vigente foi, na realidade, resultado de uma avaliação, ainda que assistemática, do desempenho destas instituições acadêmicas acerca do papel e funções estabelecidas tendo em vista a mobilização social em torno das reformas de base de que a sociedade brasileira necessitava.

Mas o nacional-desenvolvimentismo tinha seus dias contados. O redirecionamento da economia brasileira, de que o golpe militar foi um episódio marcante em termos político-institucionais, sepultou junto com projetos de desenvolvimento econômico também os projetos de uma nova universidade gestados no seio de tão ricas avaliações assistemática.

\footnotetext{
${ }^{\circ} \mathrm{O}$ projeto de modernização do País foi gestado ainda nos periodos populista e nacional desenvolvimentista, e não seria abandonado pelo regime militar-autoritário. Segundo Martins (1988, p.13), "O que sofreria uma profunda mudança qualitativa seria o sentido histórico que passaria a determinar os fins da modernização do ensino superior. Esta, a partir da liquidação política do populismo, perderia a sua conexão com a criação de um capitalismo 'autônomo', de coloração nacionalista, para tornar-se um fator instrumental da consolidação de um projeto de desenvolvimento 'associado' e dependente dos centros hegemônicos do capitalismo internacional".
} 
As demandas e conseqüências econômicas e sociais da nova fase do desenvolvimento capitalista indicavam tanto a necessidade de ampliação do acesso ao ensino superior, especialmente para a classe média, quanto impunham a racionalização das atividades universitárias para a obtenção de maior eficiência e produtividade."

\section{Que tipo de modernização era proposto nestes termos? Explicita I. Cardoso (1989,p.17):}

Educação corno instrumento de aceleração do desenvolvimento, Universidade a serviço de produção prioritária, criação de condições racionais para administração da Universidade, Universidade funcionando como uma empresa privada - com o máximo de rendimento e o mínimo investimento. (...)...as questões educacionais foram traduzidas em termos de custos e beneficios. E houve uma grande disseminação desse modo de pensar. ${ }^{12}$

Enquanto concentrava a maior parte dos recursos estatais em projetos vinculados ao fortalecimento do capital, no contexto da acelerada internacionalização da economia brasileira, o regime militar-autoritário buscava, por um lado, a associação com a iniciativa privada (via fundações, especialmente) para o empresariamento do ensino superior, e, por outro, numa clara estratégia de hegemonia, implementava formas de controle administrativo e político-ideológico desse nível do sistema de ensino. ${ }^{13}$

\footnotetext{
" Sobre o eficientismo tecnicista da Reforma Universitária, cf. Vieira (1982), em especial o Cap. 4 - Metas do Projeto da Reforma.

${ }^{12}$ Diz ainda esta autora: "Há uma evidência bastante clara dessa 'modernização' num texto de Newton Sucupira, escrito um pouco antes do GT da Reforma Universitária de 68. Nesse texto, o autor argumenta que a Universidade deve ser considerada como uma verdadeira empresa, cuja finalidade é produzir Ciência, Tecnologia e Cultura em geral. E há que se racionalizar sua produção para atingir o rnais alto grau de eficiência e produtividade. Enquanto empresa ${ }^{\mathrm{TM}} /$ generis ou forma de organização do saber, ela, na verdade, tem de estar a serviço de uma lógica da eficiência e sob o imperativo da racionalização, que é uma das categorias fundamentais da sociedade industrial moderna

${ }^{13} 1$ )Sobre as razões da adoção do modelo fundacional para as universidades federais pelo regime militar e de como essa forma jurídica de administração pública, concebida em principio para responder a objetivos de descentralização, de maior flexibilidade, agilidade e adaptabilidade administrativas, tomou-se um instrumento de promoção da privatização do ensino e de maior controle político-administrativo sobre a universidade, cf. Sguissardi ( 1993, p.23-77 e p.249-255). 2) São do final da década de 60 os Decretos-Leis $n^{\circ} 200$. de 25/2/67, e n ${ }^{\circ}$ 900, de 29/9/69, consagrados à reforma administrativa, que regulamentam, entre outras, a criação e o funcionamento de autarquias e fundações (universitárias incluídas). As fundações criadas desde então respondiam ao duplo movimento de desobrigação do Estado com o ensino superior e de recuperação/manutenção do poder de decisão e força de comando (controle político-administrativo) sobre a universidade.
} 
Os filhos da classe média, reduzidas suas possibilidades de ascensão social diante das mudanças na economia e na base científicotecnológica, invadiram as instituições de ensino superior para constituírem a preciosa clientela do novo e bem-sucedido empresariado escolar.

A demanda de mão-de-obra qualificada para suprir as necessidades do novo modelo econômico revelou-se, entretanto, limitada e de satisfação bastante rápida. Passada a fase otimista áomilagre econômico e ampliando o quadro inflacionário e de desemprego de grande contingente de bacharéis e licenciados (1975-76), os segmentos da sociedade civil envolvidos tomaram consciência de um outro gênero de inflação: o de seus títulos e credenciais acadêmicos (cf. Oliven, 1990, p.111-112; Fonseca, 1991, p.153s). A exigência de revisão crítica, visando à melhoria da qualidade do ensino e à revalorização dos títulos outorgados, passou à ordem do dia. A insatisfação cívica encontrou um Estado profundamente questionado em sua organização pelas bandeiras neoliberais do Estado mínimo, da desestatização (reprivatização) de setores estratégicos da economia e de privatização de serviços públicos essenciais como os da saúde e da educação. Subordinálos aos ditames do capital, para recuperar-lhes e garantir-lhes a eficiência e a qualidade foram as palavras de ordem que se impuseram.

Aqui, como em outros países, descontadas as especificidades de praxe, substituiu-se o discurso da democratização pelo da modernização (racionalização, otimização, excelência, eficiência etc):

Em Portugal, a política educativa evidencia nos últimos anos um deslocamento da esfera da democratização para o universo da modernização "A democratização da educação, em todos os níveis, parece ser remetida para segunda linha, como se constituísse já uma aquisição plena e um objetivo alcançado, a que haveria de se lhe juntar o objetivo da racionalização e da otimização" (Lima, 1992).

A modernização do País, e designadamente da educação e da escola, é apresentada como um desígnio nacional. Conforme já assinalamos em outro lugar, "a recuperação de atrasos, os exemplos de outros países e os desafios da integração na Europa Comunitária, as metas estatísticas, o combate ao desperdício e à ineficácia, o elogio da excelência, vão de súbito surgir como 
temas maiores e, freqüentemente, mais associados à capacidade técnica e gestionáría, e a imperativos de modernização, do que propriamente a opções políticas de fundo" (ib., ibid.). O fenômeno não é especificamente português e, pelo contrário, tem sido observado em diversos países ao longo da década anterior e do início da de noventa, com destaque para as políticas thatcherianas para a educação na Grã-Bretanha. (Lima, Afonso, 1993, p.3334; grifos nossos).

Segundo Lima e Afonso, o discurso da democratização não é afastado, mas reconvertido e subordinado à nova ideologia em função dos ganhos simbólicos e de legitimação. Constrói-se nova semântica da modernização, "que permite utilizar as mesmas palavras (democratização, participação, autonomia, descentralização, justiça social etc.) com novos significados" 14.

No caso brasileiro, os argumentos de que as universidades públicas beneficiariam apenas os ricos e, as privadas, a classe média baixa e os trabalhadores - o que significaria "na prática, um subsídio dos rnais pobres para os rnais ricos" (Schwartzman, 1994) —, e de que aumentaria cada vez rnais o descrédito em relação à instituição universitária, entre outros, serviram de razão ou pretexto para que se exigisse aumento de eficiência e produtividade do sistema público sob ameaça de corte de verbas e de imposição do estatuto da "autonomia", eufemismo regularmente utilizado para significar "privatização". Como diz Dal-Rosso (1991), "No tocante à universidade, o projeto liberal avançou as palavras de ordem da competência, do mérito, da avaliação e da autonomia".

A racionalização, a busca da eficiência etc, percorreram um caminho sinuoso desde a Reforma Universitária até o momento presente da avaliação, contemporânea do modismo da Filosofia da Qualidade Total. Passada a fase próxima da implantação da Reforma, que se fez acompanhar de todos os instrumentos, legais ou não, de repressão e controle-

\footnotetext{
${ }^{14}$ A propósito do fenômeno do "seqüestro" e da "re-semantização" de linguagens, no caso específico da Filosofia da Qualidade Total, cf. Assmann (1944), especialmente o Cap. 2, p.29-34, e, também, seu texto encaminhado à 17' Reunião Anual da ANPEd, 23-27 out. 1994, Caxambu, MG, "Ética e Sistemas Auto-Reguladores: notas sobre o sujeito ético na economia de mercado mundializada", p. 1.
} 
político-ideológico, e sobrevindo os traumas da expansão inflacionária do Ensino Superior e da desvalorização de seus títulos, reage-se oficialmente com tentativas de vinculação da universidade ao sistema produtivo através especialmente do Plano Qüinqüenal de 1975-79. Este, nas palavras de Amorin (1992, p.25),

...além de pretender expandir a oferta de ensino superior e a melhoria de sua produtividade também procurava privilegiá-lo como base de sustentação ao modelo tecnológico sofisticado vindo de fora do País. E, neste sentido, avaliava-se que a universidade brasileira deveria ter as dimensões técnicas de uma fábrica que refinaria um produto tecnológico importado, por ter exatamente os recursos humanos especializados e treinados para este fim.

A deterioração da economia e os movimentos, na sociedade civil e no interior da universidade, contra a ditadura, pela reorganização sindical, pela anistia geral, contra todos os controles político-ideológicos, conduziram o governo a responder, primeiro, com ameaças de privatização efetiva do ensino público superior, depois, com a transformação de todas as universidades autárquicas em fundações e com propostas dereformas gerenciais que apontavam para a urgente necessidade de avaliação das universidades. A ameaça completava-se com a proposta de vinculação da distribuição dos recursos do Tesouro Nacional aos resultados dessa avaliação, claramente pautada em moldes centralizadores, burocráticos, autoritários e eficientistas.

É nesse contexto, a partir de 1985, com as Comissões de Alto Nível - Grupo Executivo para a Reformulação do Ensino Superior (GERES) e Comissão Nacional pela Reformulação da Educação Superior - que, no dizer de I. Cardoso (1989, p.9), despenca de fato sobre a universidade a questão da avaliação.

Analisando os relatórios/propostas produzidos por essas duas comissões, I. Cardoso destaca antes de tudo sua questão central, traduzida no binômio autonomia-avaliação e acrescenta:

Tal distinção, na verdade, é uma questão meramente analítica, na medida em que tanto a questão do procedimento (constituição das "co- 
missões de alto nível") quanto o conteúdo do projeto da avaliação estão subordinados a um mesmo tipo de lógica, que é a lógica da eficiência ( $\mathrm{g}$ if os nossos).

Refere-se I. Cardoso à tradição centralizadora e autoritária do Estado brasileiro, de criar comissões de alto nível (GT da Reforma Universitária, por exemplo), de legislar/ pelo alto, sem nenhum tipo de debate (Leis 5.540/68 e 5.692/71, entre outras), sempre tendo como pressuposto absoluto

...a desqualificação dos princípios democráticos e liberais por parte dos sábios da República, em nome da Ciência e do realismo político, ou seja, das questões da eficiência. Isso implica no descarte puro e simples da premissa de que o sujeito da atividade universitária pode e deve legislar sobre o seu agir. Essa recusa do debate e da discussão - que, na linguagem atual da Nova Republica, é chamada "recusa ao assembleísmo" — implica sempre na afirmação dos critérios científicos na condução da política universitária e, portanto, na adoção do que chamaríamos lógica da eficiência.

Fica evidente, tanto pelos documentos oficiais mais importantes quanto por pronunciamentos dos titulares do MEC nos últimos dez a quize anos, que as propostas oficiais de avaliação se fundam invariavelmente, apesar da linguagem mais ou menos disfarçada, nas idéias de eficiência, de produtividade, correspondentes à concepção neoliberal de modernização ${ }^{15}$ ou, simplesmente, à lógica do capital no desenvolvimento da sociedade contemporânea. O disfarce pode estar em pomposos slogans "Uma Nova Política para a Educação Superior", "Projeto para uma Nova Universidade", "Educação para Todos" etc.

\footnotetext{
${ }^{15} \mathrm{O}$ conceito de modernização nos termos acima toma conta também de importantes setores do Congresso Nacional. Verifique-se os termos do Cap.XIII do Projeto de LDB em fase de aprovação final naquela Casa. que trata da avaliação de instituições de ensino superior. "Reduzindo esta avaliação aum simples mecanismo de aferição do 'padrão científico' dessas instituições, o texto estabelece que o processo de avaliação seja feito para fins de 'credenciamento como universidades', pelo Poder Público, das instituições que comprovem 'alta qualificação científica, nos termos da lei" (Moraes, 1991. p.45). Observe-se que esta idéia de "credenciamento" através de processos de avaliação institucional pelo Poder Público, e mediante o critério da qualidade, já constava das sugestões do relatório "Uma Nova Política para a Educação Superior", da Comissão Nacional para Reformulação da Educação Superior, de nov.1985.
} 
Referindo-se ao caso português e demonstrando a globalização de certos fenômenos, dizem Lima e Afonso (1993, p.34):

Registre-se ainda uma tendência no sentido de remeter a democratização para o discurso político e normativo rnais visível, presente em leis fundamentais, em preâmbulos, na apresentação pública de programas e medidas governamentais, ao passo que o discurso da modernização tende a estar presente de forma rnais constante nos domínios da regulamentação e da ação política, domínios rnais operativos e implementativos e, por isso, aparentemente menos sujeitos a critérios de conveniência discursiva. (...) Porém, rnais recentemente, tem-se assistido a uma defesa rnais aberta, e por vezes mesmo apologética, da modernizaçãoracionalizaçào educativa por parte de certos setores, não obstante se descortinarem nuanças entre discursos proferidos por diferentes responsáveis e se dever admitir que a expressão da política educativa não se constitui necessariamente como um corpo monolítico, absolutamente estável e congruente.

Como disfarce para as razões objetivas tem-se proclamado a necessidade e a obrigatoriedade da avaliação, especialmente fundamentando-a no conceito de direito social.

A necessidade da avaliação é justificada porque se considera que a Universidade tem obrigação de dar resposta à "sociedade", de onde provêm os recursos que a sustentam a partir dos contribuintes, aos quais se deve prestar contas da aplicação dos recursos investidos e da produtividade desse investimento. Cabe notar que a sociedade é tratada como um conjunto, naturalmente diferenciado, de contribuintes, com o sentido subjacente de que, quem paga, por isso tem direito.

O argumento é muito distante da concepção de educação como um bem que é direito de todo produção universitária e sua compatibilidade com as prerrogativas próprias da cidadania, com seu rol de direitos a respeitar e de necessidades a atender. Muito longe disto está a proposta oficial de avaliação. (M.L.Cardoso, 1991, p.15).

Tenta-se igualmente justificar a necessidade de avaliação como contrapartida da autonomia concedida à universidade, uma espécie de com- 
provação social de sua eficiência. Antes de tudo, deve-se dizer que o famoso estatuto da autonomia universitária, no Brasil, jamais foi respeitado. No caso das universidades federais, não existe no âmbito financeiro a decantada autonomia, senão apenas entendida como gestão financeira dos recursos que sejam repassados pelo governo nos tempos e prazos que lhe convenham (os repasses de verbas orçamentárias têm sido efetuados habitualmente sem respeito a qualquer norma de boa administração). Nos âmbitos administrativo e acadêmico, as universidades federais têm sido impedidas de exercer qualquer autonomia, seja na contratação de recursos humanos, seja na abertura de cursos de qualquer natureza, nos últimos 10 a 15 anos.

M. L. Cardoso chama a atenção para a especificidade da universidade como lugar de formação e de produção científica e tecnológica que a distingue dos demais setores da burocracia estatal, à qual não poderiam ser aplicadas as normas burocráticas gerais, sob pena de a universidade perder sua capacidade de produção com as características que deveriam lhe ser próprias.

No fundo, é isso que embasa a pretensão de autonomia didática, pedagógica, de pesquisa e de gestão financeira por parte das universidades. A autonomia, assim, não procede de nenhuma concessão para a qual se exija ou se deva exigir uma contrapartida.

A questão da autonomia, rnais uma vez, tem de ser vista como o verdadeiro fundamento da independência institucional da universidade para a busca da verdade sem restrições. Como diz I. Cardoso (1989, p.10), isto significa "que a sociedade — ou o Estado em nome dela não poderia impor regras, limites ou restrições à atividade estritamente acadêmica da instituição".

A lógica da eficiência, que incorpora a universidade ao processo de planificação global realizado pelo Estado e a subordina ao mesmo grau e ao mesmo tipo de realismo político que orienta as decisões relativas a outros setores da sociedade, é inteiramente incompatível com o debate e a discussão (Id. ibid., p.15). 
Para justificar a adoção de processos avaliativos recorre-se ainda a argumentos como: a) o absoluto consenso que haveria na comunidade universitária quanto à sua importância (sem qualquer referência ao tipo de avaliação, a quem se solicita, para que finalidade etc); b) as atividades universitárias "não podem rnais ser desenvolvidas a qualquer custo"; c) sem avaliação não se pode "conhecer a relevância social dos objetivos propostos, bem como a eficácia, o impacto e a eficiência das ações realizadas"; d) a necessidade de "romper a entropia interna das universidades".

No dizer de Vahl (s.d., p.l), já não se discutiria rnais, hoje, a necessidade de avaliação no ensino superior, e simo quê, como, quando e a quem compete avaliar. Isto, entretanto, é uma verdade apenas parcial. Um simples comentário à questão que Vahl encaminha em seqüência por que ela não é praticada ou praticada de forma tímida? - tentará demonstrá-lo. A resposta a esta questão está contida na formulação mesma de sua primeira afirmativa. A convicção generalizada quanto à necessidade da avaliação é apenas de princípio. Para se tornar prática efetiva junto a uma instituição que preze minimamente o estatuto da autonomia é preciso antes existir acordo quanto às respostas às quatro questões postas acima. Esse acordo, e somente ele, pode garantir o início e o eventual êxito desse processo, sem que com isso se desconsidere eventuais atitudes de resistência e de autodefesa decorrentes da associação da avaliação a idéias tantas vezes presentes de auditoria e de punição.

\section{Alguns princípios, parâmetros ou critérios para avaliar a avaliação no ensino superior}

A definição de alguns princípios, parâmetros ou critérios para avaliar propostas de avaliação no ensino superior deve começar pelas respostas a questões tais como: a) o que de fato fundamenta e justifica a avaliação? b) para que serve a avaliação? c) quais as principais questões que têm sido levantadas diante das propostas de avaliação de iniciativa 
oficial e mais recentemente também de iniciativa de organismos ligados a entidades empresariais privadas?

Como se disse páginas atrás, nos termos de M. L. Cardoso, o processo de avaliação pode ser um instrumento importante de elevação da qualidade do trabalho acadêmico e conduzir à construção de uma universidade produtora e crítica, assim como pode tornar muito rnais eficaz e eficiente uma universidade voltada para a reprodução da ordem estabelecida, na ótica do capital. Essa distinção reclama, segundo essa autora, uma profunda reflexão a respeito do conceito de qualidade da universidade.

O primeiro dos aspectos da qualidade refere-se a seu caráter nãouniversal, ao contrário do que tentam fazer crer propostas oficiais e/ou defendidas por lideranças empresariais. M. L. Cardoso aponta fundamentalmente duas noções de qualidade. A primeira, de cunho empresarial, identificada com eficiência e produtividade, que levaria a concentrar tanto formação quanto produção em poucas instituições, que o Geres denominou universidades de conhecimento (por oposição a universidades de ensino), e que também foram conhecidas como centros de excelência. A segunda seria a acadêmico-crítica e que, nas suas palavras,

Toma como referência o $3^{\circ}$ grau enquanto um conjunto, de forma a integrar ensino e pesquisa em cada uma das universidades que o constituem. Nesta concepção de qualidade, o que é central e decisivo se situa além da mera produtividade como medida do desempenho de cada instituição, mas, diferentemente, toma como eixo norteador a capacidade de produção, intrinsecamente considerada, da instituição universitária. Trata-se menos de quanto se produz, a que velocidade e a que custo, mas principalmente do que se produz, certamente também considerando o tempo e o custo dessa produção. Trata-se aí de avaliar a importância acadêmica, científica, tecnológica, sócio-política ou econômica da produção universitária.

(...) o cerne da questão consiste na importância, para a ciência e para a sociedade, do trabalho realizado, avaliado pela comunidade acadêmico-científica, em particular, e pela comunidade em geral. Esta avaliação não é fácil e supõe critérios claros, explícitos e concretos, embora delicados e flexíveis, devendo necessariamente incluir trabalho continuado e dedicado. 
O estudo já referido de Lima e Afonso contribui para entender-se melhor o significado da visão modernizadora ou empresarial de avaliação. Esses autores analisam como o neotaylorismo apresenta-se, na educação, na forma do ressurgimento de teorias organizacionais de tipo neocientífico, combinando de modo complexo elementos de relações humanas, teoria da contingência, do desenvolvimento organizacional, passando por "novo corpo de idéias e de propostas modernas, produzindo freqüentemente situações de um certo encantamento e de uma certa adesão, mesmo em setores políticos e sociais de 'oposição'"

As palavras-chave dessas ideologias gestionárías ou do discurso da modernização, lá como cá, são: empresa, capacidade, competência, racionalização, eficácia, controle de qualidade, etc. Resumindo, "tornase indispensável racionalizar e otimizar, garantir a eficácia e a eficiência".

A modernização de tipo neotayloriano institui uma racionalidade tecnocrática assente na "cultura do positivismo", relegando "a natureza política da escola à sala de espera da teoria e práticas educativas", como observa Henry Giroux (1986, p.223). A racionalidade técnica, no sentido de Habermas, oposta à racionalidade hermenêutica e à racionalidade emancipatória, é certa e objetiva, acentua o controle e a mensuração dos resultados, é neutra e livre, ou acima de valores. Ignora que cada modo de racionalidade se baseia num sistema de valores e de interesses ou, quando muito, qual "varinha mágica", como escrevem Correia, Stoleroff e Stoer (1993) a propósito da modernização, eleva os interesses particulares à categoria de interesses universais (Lima, Afonso, p.35). ${ }^{\mathrm{I} 6}$

\footnotetext{
${ }^{16}$ A respeito da onda avaliativa acrescentam: "A obsessão pela eficácia, pela eficiência e pela qualidade, ainda que recente no universo educativo, é uma obsessão tipicamente tayloriana, presente de diversas formas na teoria da burocracia, na escola das relações humanas, nas perspectivas sistêmicas e contingenciais etc. A novidade residirá, apenas, na insistência com que é referida no setor educativo, ganhando foros de inovação. A reedição de programas, de métodos e de técnicas que têm feito carreira na administração de empresas, sobretudo a partir da década de 60, agora, no contexto educativo, é rnais um sinal a confirmar a adoção de um modo de racionalidade econômica" (p.36). A ideologia organizativa do tipo neotayloriano penetra profundamente nas matérias avaliativas, as quais, de resto, ganham súbita e redobrada importância política. A avaliação neotayloriana concentra-se nos resultados obtidos, assume os objetivos como consensuais e definidos a priori, e as tecnologias pedagógicas e de
} 
As medidas de racionalização são, cada vez mais, acompanhadas do corte das despesas públicas e do discurso habitualmente reiterado do "esgotamento das possibilidades de atendimento [educacional] por parte dos governos"(CF. Schwartzman, 1992, p.23; Durham, 1994).

$\mathrm{O}$ que tem sido a marca das propostas oficiais de avaliação do ensino superior é a freqüente desconsideração de que: a) a avaliação e o que se avalia, portanto sua qualidade, ocorrem em condições concretas e específicas de cada instituição; b) avaliar uma instituição não se reduz à soma de escores individuais de desempenho de professores; c) não existe avaliação que mereça esse nome se não se avaliar as condições efetivas oferecidas à e pela instituição para a produção acadêmica (pesquisa, ensino, extensão, etc); e d) a existência de um projeto institucional e de uma política acadêmica é referência básica para o estabelecimento de qualquer critério ou processo de avaliação.

Com referência específica a este último item, costuma-se atribuir aos operadores situados no final do circuito do processo educacional

...a responsabilidade pela qualidade do produto desse processo e pelo próprio processo, deixando fora da análise a política educacional que está na sua origem e que, deste modo, não encontrará lugar nem momento para ser questionada (Schwartzman, 1992, p.14).

O mesmo vale para os conceitos de competência, de excelência e de produtividade. Costuma-se fazer a mais pura abstração das ricas cadeias de mediações e do processo histórico de sua produção que explicam os escores finais individuais de carga didática por professor, número de orientandos por orientador etc.

avaliação como processos certos, estáveis e objetivos.[ ] esse tipo de avaliação releva "[ ]de um projeto de controle da subjetividade e de esbatimento da 'imperfeição humana', centrado nos resultados obtidos e no rigor Ias formas de tradução/quantificação desses resultados - 'critérios de objetividade', 'medição', 'validação externa', 'verificação da qualidade', 'aferição',' validade efidedignidade'etc. Convoca-se uma monorracionalidade e tipo técnico e uma perspectiva gestionária-utilitária (neotayloriana), decompõe-se e fragmenta-se o processo e avaliação, quantificando, mensurando, formalizando; adota-se uma visão mecanicista da organização escolar. entrada nas operações técnicas, na eficácia e na eficiência"(p.38). 
Como entender, por exemplo, o conceito de competência? Nos estritos limites da função escolar reprodutiva das relações sociais, que diferencia, hierarquiza, exclui, controla e disciplina, para a manutenção da ordem estabelecida? Ou no sentido de capacidade de ultrapassar os estreitos limites da inculcação valorativa propiciada pela escola na ótica do modo capitalista de pensar e de viver, em que a busca de eficiência e do constante aumento da produtividade, da relação entre investimento e produto e entre ganhos e perdas, sempre norteia ações e tomadas de decisão? (Id. ibid, p.18).

Na perspectiva de um sistema de avaliação institucionalacadêmico-crítico, que supere os limites da reprodução da ordem, a competência deveria referir-se à capacidade e à habilidade de contribuir para se ultrapassar as demandas imediatas do mercado de trabalho, para se desenvolver a capacidade de pensar criticamente e de produzir conhecimento, liberto dos controles burocráticos e do poder. De outro modo, "a competência continua sendo peça-chave para a reprodução do status quo e a sua conseqüente manutenção legitimada" (Id. ibid.).

Esta concepção de avaliação institucional possibilitaria não somente a aferição de dados quantitativos relativos aos produtos e processos em curso, mas permitiria localizar os fatores condicionantes desses processos, entre os quais jamais se deve esquecer a dotação de recursos e sua distribuição, "seja nos projetos institucionais e sociais, seja na própria execução do trabalho universitário através de professores, pesquisadores, administradores e técnicos".

Sob esse ponto de vista, a qualidade da universidade depende da disponibilidade de condições técnicas, profissionais e financeiras, bem como de condições de funcionamento democrático da gestão da universidade, especialmente quanto à tomada de decisões e também, mas não meramente, do competente exercício docente no sentido estrito. Levantar a questão da avaliação desse ponto de vista significa questionar o funcionamento das universidades no Brasil, chamando a atenção, no entanto, para os condicionamentos que no fundo se considera como historicamente responsáveis pela 
situação atual, tendendo assim a encaminhar propostas capazes de conduzir à elevação do padrão de qualidade do conjunto do sistema universitário brasileiro, atuando em todos os níveis de determinação da sua realidade neste momento. (Id. ibid., p.19).

Fora dessa perspectiva, a universidade brasileira continuará sendo visualizada por óticas funcionalistas e sistêmicas, fundadas em racionalidades a priori, como também ocorre em países do Primeiro Mundo - Holanda, França (Lima, Afonso, op. cit. p.18) e Inglaterra (Neave, 1988), por exemplo, e que são mais e mais questionadas, não somente em face das tradições seculares de autonomia universitária, nesses países, como também em face de importantes especificidades do multifacetado sistema de ensino superior, tanto aqui como no exterior. A racionalidade da avaliação da qualidade tomada como valor universal pressupõe objetivos claros e consensuais, tecnologias certas e estáveis, consistência e conexão entre planejamento e ação, políticas e resultados, e ignora o sentido específico da atividade universitária, que repousa na liberdade e na autonomia acadêmicas de decidir por si só o quê e como ensinar, o quê e como pesquisar, e que é isto que constitui a verdadeira essência e pedagogia da universidade.

Do exposto até aqui fica evidente, antes de tudo, que o acordo geral sobre a necessidade de avaliação do ensino superior, se existe, apresenta-se muito precário, porque fundado em princípios de igual fragilidade. $\mathrm{O}$ exame de diferentes propostas quanto às concepções teórico-práticas ou político-acadêmicas que as fundamentam torna evidentes as grandes divergências que explicam em boa medida a indefinição desse campo. E que explicam também os entusiasmos desmedidos ou as consistentes resistências de que são alvo. Estas, as resistências, na aparente contramão da história, têm sido oficial e oficiosamente denominadas corporativas, ao arrepio de seu verdadeiro significado.

Por outro lado, para que o acordo seja possível numa extensão muito maior, ao menos entre os que acreditam na avaliação institucional, aqui denominada acadêmico-critica, como um eventual precioso instrumento de democratização da universidade, é hora de se sistematizar al- 
guns princípios, parâmetros ou critérios para subsidiar o exame de propostas de avaliação do ensino superior.

Kipnis (1991), refletindo sobre a rica experiência de avaliação institucional interna promovida na Universidade de Brasília, propõe alguns princípios que deveriam nortear o processo avaliativo: legitimidade, participação, integração, não- punição/premiação, compromisso, continuidade e sistematização. A legitimidade pressupõe o acordo da comunidade acadêmica quanto aos critérios e quanto à institucionalização do processo de avaliação. A participação $\hat{e}$ entendida como a atuação responsável dos diferentes segmentos institucionais em todas fases do processo de avaliação. A integração ou intercâmbio de esforços e experiências preexistentes ou concomitantes, de modo a integrá-los no processo global de avaliação institucional. Não-punição/premiação, princípio posto para exorcizar esta característica de propostas racionalizadoras e autoritárias e substituí-la pela "identificação de metas e correção de rumos". O compromisso deve ser tanto individual como coletivo na busca do aperfeiçoamento institucional. Por último, o princípio da garantia da continuidade e sistematização desse processo como reflexão e redefinição constantes dos objetivos, das metas, das prioridades acadêmico-científicas e sociais da instituição universitária.

Desses, o princípio estrategicamente rnais importante talvez seja o primeiro - o da legitimidade —, pois subentende, embora não de modo exclusivo, o respeito básico ao estatuto da autonomia, nos termos expostos páginas atrás, e é condição insubstituível de qualquer processo de avaliação na perspectiva político-institucional adotada no presente texto.

M. L. Cardoso (1991, p.22-23), cujo estudo é aqui tomado como referência especial, apresenta um conjunto de idéias que podem servir de parâmetros ou critérios para o objetivo aqui estabelecido:

- Uma proposta ou um processo de avaliação é função de um projeto de desenvolvimento da sociedade. Isto pressuposto, tornam-se obrigatórias questões como: De que competência se trata? Competência para quê? Competência para integrar-se e servir a (ou questionar) que tipo de sociedade? 
- Uma proposta ou um processo de avaliação traz em si e contribui para implantar ou fortalecer um dado padrão de política educacional e/ou de universidade. E isto precede à discussão imediatamente técnica que pergunta quem e como avalia. Antes devem ser formuladas questões como: Qual universidade? Universidade para quê?

- Admitida a necessidade da avaliação, esse processo deveria abranger todo o sistema escolar e todas as suas atividades, voltado para a elevação da qualidade da educação nacional em todos os graus da rede pública e privada.

- A avaliação deve estender-se à totalidade das atividades da instituição objeto desse processo.

- A avaliação deve ser ampla, global e se iniciar com a universidade enquanto instituição: cada universidade tem um perfil, tem uma história. É preciso identificar esse perfil, reconstituir essa história, para avaliar o papel que essa universidade específica tem desempenhado historicamente na sociedade e diante do desenvolvimento da ciência e colocá-lo em discussão, especialmente para definir se é isso mesmo que a comunidade universitária (e também a comunidade em geral) quer(em) para essa universidade neste momento e no futuro próximo.

- Nesse tipo de avaliação institucional global é básica a análise das verbas com as quais trabalha a universidade: quanto recebe, de que fonte(s) e de que forma (global, parcelada); por outro lado, como são distribuídos internamente esses recursos (quem decide, critérios, setores contemplados, regularidade).

- Para que a avaliação institucional global seja completa é preciso analisar e avaliar o processo decisório no interior da universidade: Quem decide e como são tomadas as decisões (se existem ou não mecanismos públicos de controle sobre o processo de tomada de decisões)? Qual o grau de abertura e de flexibilidade da estrutura de poder dentro da universidade em relação à sociedade? Que lugar ocupam e qual a importância que os movimentos sociais organizados têm nas deliberações?

- A avaliação do desempenho acadêmico, como parte da avaliação institucional global, deve incluir todas as atividades de ensino (professores, 
monitores, estudantes), pesquisa (pesquisadores, técnicos) e administração (em todos os níveis, envolvendo desde os servidores que ocupam os cargos rnais simples até os dirigentes máximos das instituições). O processo deve abranger, por um lado, unidades e departamentos e, por outro, os cursos, e só então o professor e o pesquisador individuais.

- Um processo de avaliação institucional global dessa natureza deve ser explícito e claro e pressupõe um projeto de universidade, que seja legítimo pela forma de sua construção, resultante de discussão aberta, ampla e democrática, livre e coletiva, e oposta a qualquer imposição de tipo tecnocrático.

- O centro desse projeto de universidade é uma política acadêmica, que compreende fundamentalmente uma política de ensino, uma política de pesquisa, uma política de extensão e uma política administrativa presumivelmente associadas.

Para M. L. Cardoso (1991, p.23-24), a marca distintiva da universidade produtora de qualidade é a produção do saber (pesquisa científica e tecnológica, o desenvolvimento do saber de ponta, a pesquisa básica, a pesquisa filosófica e artística) e sua indissociabilidade com o ensino.

Com o projeto de universidade e a política acadêmica, o que se objetiva, nas suas palavras,

...é a construção de um perfil/projeto real/desejado para universidade em questão. Essa construção terá de atender às muitas especificidades que cada universidade contém. Por isso, a proposta é que ela se dê desde a unidade menor da produção na universidade (seja área, departamento, escola ou instituição) até a universidade como uma globalidade. Assim, o projeto de universidade com suas políticas específicas será colocado tanto no plano geral, da própria universidade ou de um conjunto de universidades, quanto no plano particular de departamentos, unidades ou centros. A compatibilidade entre essas especificidades é que garantirá a construção de uma política acadêmica verdadeiramente universitária, fazendo avançar os projetos e suas políticas científica, tecnológica, cultural..

Aos princípios sugeridos por Kipnis e às idéias apresentadas por M. L. Cardoso, para concluir, acrescentem-se (respeitando-se a integri- 
dade dos enunciados, mesmo que haja superposição) princípios e idéias contidos nos artigos 83 a 87 do Projeto da Associação Nacional de Docentes do Ensino Superior (Andes-SN) para a Lei de Diretrizes e Bases da Educação Nacional (LDB) de 1991: ${ }^{17}$

- Os processos de avaliação interna e externa serão democráticos, legítimos e transparentes.

- O processo de avaliação interna deve ser entendido como: a) retrospectiva crítica, socialmente contextualizada, construída na discussão pública e democrática do trabalho realizado pela instituição; b) parte integrante do processo de construção da escola pública e democrática, na gestão e no acesso; c) instrumento para o controle social da atividade do Estado na esfera da Educação; d) ação geradora da construção de um projeto de desenvolvimento acadêmico e científico.

- O processo de avaliação do trabalho institucional e acadêmico deve ser responsabilidade das instâncias em que é realizado, e seu caráter deve ser público, democrático e pluralista no que diz respeito a idéias e concepções. Este processo deverá ter como referência as condições concretas em que ele ocorre: verbas, salários, insumos materiais, instalações e condições sociais, econômicas e políticas.

- O processo de avaliação do trabalho acadêmico de cada docente terá como objetivo o estímulo ao aprimoramento de suas atividades de ensino, pesquisa e extensão e a compreensão de sua articulação com o projeto global da unidade acadêmica e da instituição.

- O processo de avaliação externa das Instituições de Ensino Superior (IES) públicas (e das IES privadas que utilizem recursos públicos) será realizado, em cada estado e no Distrito Federal, por um Conselho Social de natureza autônoma e de caráter consultivo, que expresse os interesses substantivos dos diferentes setores da sociedade em que se insere, tendo como função precípua contribuir para a formulação de políticas acadêmicas e financeiras das IES públicas.

"UNIVERSIDADE E SOCIEDADE, v.I.n.l.fev. 1991, Encarte, p.17-18. 


\section{Conclusão: pontos para o estudo da temática da avaliação no ensino superior}

Como conclusão, relacionam-se a seguir, sem ordem de prioridade, alguns pontos da temática da avaliação que poderiam ser objeto de aprofundamento teòrico-critico dos pesquisadores interessados na temática do ensino superior em futuros estudos e pesquisas.

- A partir dos princípios, parâmetros ou critérios acima, exame de diferentes propostas de avaliação do ensino superior, tais como a Proposta da Andes-SN, da Associação Nacional dos Dirigentes de Instituições Federais de Ensino Superior (Andifes), ou de processos de avaliação mais ou menos sistematizados, em andamento na Universidade de São Paulo (USP), na Universidade Estadual de Campinas (Unicamp), em IESs privadas etc.

— Estudo do significado da avaliação externa, especialmente quanto às suas possibilidades de tornar-se fator condicionador de opções pedagógicas e profissionais ou constrangedor da autonomia institucional e profissional, de modo particular se tais processos conduzirem à introdução da comparação de resultados entre instituições.

- Estudo do advento do neotaylorismo na gestão empresarial atual e no sistema educacional oficial ou privado e sua presença nas propostas de avaliação educacional, assim como dos discursos da qualidade e da competência e suas referências a padrões empresariais.

- Estudo dos fundamentos teórico-científicos e político-acadêmicos das propostas de avaliação fundadas na Filosofia e na Pedagogia da Qualidade Total.

- Estudo dos conceitos de público e privado e de sua relação com propostas de avaliação do ensino superior.

— Estudo da relação entre avaliação e política de privatização do ensino superior.

— Estudo do significado das adesões e das resistências à implantação de processos de avaliação no ensino superior. 
- Estudo do impacto de processos de avaliação fundados em concepções e práticas divergentes entre si sobre as instituições envolvidas e sobre sua imagem social.

\section{Referências bibliográficas}

ADUFSCar. Fundamentos para avaliação institucional - Andes-SN1991. São Carlos, Assembléia Geral, 17 dez. 1993. mimeo.

AMORIN, Antônio. Avaliação institucional da universidade. São Paulo: Cortez, 1992.

ANDES. Proposta das Associações de Docentes e da Andes para a Universidade Brasileira, [s.l.: s.n.], 1982. Mimeo.

ANDIFES. Uma Proposta de Avaliação das Instituições de Ensino Superior. Documento Preliminar da Comissão de Avaliação, Florianópolis, out. 1993.

ASSMANN, Hugo. Paradigmas Educacionais e Corporeidade. Piracicaba: Ed. UNIMEP, $1993^{\mathrm{a}}$

"Pedagogia da qualidade" em debate". Texto apresentado no Seminário Temático no III Congresso Estadual Paulista sobre a Formação de Educadores, Águas de São Pedro, SP, 22-23 maio 1994.

Qualidade/qualidade total: patranhada ideológica e desafio real. Piracicaba: UNIMEP, 1993b mimeo.

AVALIAÇÃO: trabalho intelectual e avaliação acadêmica. Cadernos ANDES, Juiz de Fora, n. 7, dez.1987 (II Seminário Nacional, Rio, dez.1987; Avaliação institucional. Texto da diretoria para o XIII Congresso da Andes, Viçosa, 1994). 
BELLONI, Isaura; KIPNIS, Bernardo; SERAFINI, Oscar. Avaliação do ensino de graduação: teste da metodologia-1987. Brasília: Ed. UnB, 1988.

BUARQUE, Cristovam. A aventura da universidade. São Paulo: Ed. UNESP; Rio de Janeiro: Paz e Terra, 1994.

. Uma idéia de universidade. Brasília: Ed. UnB, 1986.

CARDOSO, Irene. A avaliação acadêmica e as fundações. Cadernos ANDES, n.7, p.7-35, fev. 1989.

CARDOSO, Miriam L. A Avaliação da universidade: concepções e perspectivas Universidade e Sociedade. Brasília, V.l, n.1, p.14-24, set. 1991.

DAL-ROSSO, Sadi. Universidade e sociedade: um instrumento para a ação. Universidade e Sociedade, Brasília, v. 1, n.l, p.5-6, fev. 1991.

DURHAM, Eunice. Estrutura irracional e perdulária.Folha de S. Paulo, 21 maio 1994. p.3. el.

FONSECA, Dirce Mendes da. O pensamento privatista em educação. Campinas: Papirus, 1992.

KIPNIS, Bernardo. Avaliação interna da universidade: princípios, metodologia e estratégia política. Texto apresentado na mesa redonda "Avaliação do Ensino Superior", da VI CBE, São Paulo, 5 set. 1991.

KOURGANOFF, Wladimir. A face oculta da universidade. São Paulo: Ed. UNESP, 1990.

LIMA, Licinio C; AFONSO, Almerindo J. A emergência de políticas de racionalização, de avaliação e de controle da qualidade na reforma educativa em Portugal.Educação \& Sociedade, Campinas, n.44, p.33-49, abril 1993. 
MARTINS, Carlos B. O novo ensino superior no Brasil. In:

(Org.). Ensino Superior Brasileiro: transformações e perspectivas. São Paulo: Brasiliense, 1988, p. 13).

MORAES, Ignez Navarro de. Educação Brasileira: uma nova lei de diretrizes e bases. Universidade e Sociedade. Brasília: ANDES, V.l, n.l, p.37-47, fev.1991.

NEAVE, Guy. On the cultivation of quality, efficienty and enterprise an overview of recent trends in higher education in Europe, 1986-1988. European Journal of Education, v.23, n.1/2,p.7-24, 1988.

OLIVEIRA, Francisco de. Universitários, Uni-vos. Universidade e Sociedade. Brasília: ANDES, V.1, n.2, p.7-9, nov.1991.

OLIVEN, Arabela C. A paroquialização do ensino superior, classe média e sistema educacional no Brasil. Petrópolis: Vozes, 1990.

PAUL, Jean-Jacques; RIBEIRO, Zoya; PILATTI, Orlando. As iniciativas e as experiências de avaliação do ensino superior: balanço crítico. In: DURHAM, Eunice R; SCHWARTZMAN, Simon. Avaliação do ensino superior. São Paulo: EDUSP, 1992, p.141-167.

PLATAFORMA dos docentes do ensino superior para a Constituinte. Cadernos da Andes, Brasília, n.4, maio 1987.

PROPOSTA das associações de docentes e da Andes para a universidade brasileira. Caderno Andes, Juiz de Fora, n.2, jul.1986.

SAUL, Ana Maria. Avaliação emancipatório: desafio à teoria e à prática de avaliação e reformulação de currículo. São Paulo: Cortez:Autores Associados, 1988. 
SCHWARTZMAN, Simon. O contexto institucional e político da avaliação. In: SCHWARTZMAN, Simon; DURHAM, Eunice R. . (Orgs.) Avaliação do ensino superior. São Paulo: EDUSP, 1992. p. 13-27.

Uma política para o ensino superior. Folha de S. Paulo, 4jun.1994. p. 3. c.l.

SCHWARTZMAN, Simon; DURHAM, Eunice. Avaliação do ensino superior. São Paulo: EDUSP, 1992.

SGUISSARDI, Valdemar. Universidade, fundação e autoritarismo: o caso da UFSCar. São Paulo: Estação Liberdade; São Carlos: EDUFSCar, 1993.

SGUISSARDI, Valdemar; SILVA JR, João dos Reis. As Novas Faces do ensino superior privado. Comunicação apresentada na $17^{\mathrm{a}}$ - Reunião Anual da ANPEd, Caxambu, 23-27 de out. 1994., mimeo.

SILVA JR, João dos Reis. Qualidade total no ensino superior: ideologia administrativa e impossibilidade teórica. Texto apresentado na $17^{\mathrm{a}} \mathrm{Reu}-$ nião Anual da ANPEd, Caxambu, 23-27 out. 1994, Caxambu-MG.

UNIVERSIDADE E SOCIEDADE, Brasília, V.1, n.1, fev. 1991. Encarte de $24 p$., entre p.50-51.

VAHL, Teodoro R. O papel da avaliação na gestão universitária. Florianópolis: UFSC/NUPEAU, s.d. (Série textos).

VIEIRA, Sofia L. O (dis)curso da (re)forma universitária. Fortaleza: Ed. UFC/PROED, 1982.

WOLFF, Robert P. O Ideal da universidade. São Paulo: Ed. UNESP, 1993. 
Recebido em 3 de março de 1996.

Valdemar Sguissardi é professor e coordenador do Programa de Pós-Graduação da Universidade Metodista de Piracicaba (Unimep), SP.

Within the process of new-liberal modernization, which affects all levels of Brazilian society and government today, the movement related to the assessment of higher education is noteworthy. This article aims, on one hand, to retrieve the origins, motivations and the identity of this movement and, on the other hand, to establish some parameters for the critical examination of the different higher education assessment proposals presented by public and private institutions or others socials organizations. Concluding, the author suggests discussion topics related to the assessment of higher education for reserchers in the area, themes which, if analized and questioned, could become objects of future study and research.

L'évaluation de l'enseignement supérieur est un mouvement qui gagne, à chaque jour, une place plus importante à l'intérieur du processus de modernisation néo-libérale, qui affecte toutes les instances de l'État et de la société brésilienne d'aujourd'hui. Cet article vise, d'un côté, à la récupération des origines, des motivations et de l'identité de ce mouvement et, de l'autre côté, à l'établissement de critères pour l'examen critique des différentes propositions d'évaluation de ce niveau d'enseignement faites par des institutions publiques et privées et par d'autres organisations sociales. Pour conclure, l'auteur propose aux chercheurs de ce niveau d'enseignement (enseignement supérieur) un certain nombre de problèmes liés à cette thématique qui pourraient être pris en tant qu'objets de futures études et recherches. 
En el ámbito del proceso de modernización neoliberal, que afecta hoy a todas las instancias del Estado y de la sociedad brasileña, gana relieve el movimiento de evaluación de la enseñanza superior. Este artículo se propone, por una parte, recuperar los orígenes, motivaciones e identidad de ese movimiento y, por otra, establecer algunos parámetros para un examen crítico de las distintas propuestas de evaluación de ese nivel de enseñanza planteadas por instituciones públicas y privadas y otras entidades u organizaciones sociales. Para concluir, el autor propone a los investigadores del área (enseñanza superior) un punteo de tópicos temáticos para la evaluación de la enseñanza superior que, debidamente problematizados, podrían volverse objetos de futuros estudios $e$ investigaciones 